\title{
Seasonal patterns of water storage as signatures of the climatological equilibrium between resource and demand
}

\author{
B. François ${ }^{1,2}$, B. Hingray ${ }^{1,2}$, F. Hendrickx ${ }^{3}$, and J. D. Creutin ${ }^{1,2}$ \\ ${ }^{1}$ CNRS, LTHE - UMR5564, 38041 Grenoble, France \\ ${ }^{2}$ University Grenoble Alpes, LTHE - UMR5564, 38041 Grenoble, France \\ ${ }^{3}$ EDF, R\&D, LNHE, 78400 Chatou, France
}

Correspondence to: B. François (benoit.hingray@ujf-grenoble.fr)

Received: 26 June 2013 - Published in Hydrol. Earth Syst. Sci. Discuss.: 10 July 2013

Revised: 16 August 2014 - Accepted: 21 August 2014 - Published: 30 September 2014

\begin{abstract}
Water is accumulated in reservoirs to adapt in time the availability of the resource to various demands like hydropower production, irrigation, water supply or ecological constraints. Deterministic dynamic programming retrospectively optimizes the use of the resource during a given time period. One of its by-products is the estimation of the marginal storage water value (MSWV), defined by the marginal value of the future goods and benefits obtained from an additional unit of storage water volume. Knowledge of the MSWV makes it possible to determine a posteriori the storage requirement scheme that would have led to the best equilibrium between the resource and the demand. The MSWV depends on the water level in the reservoir and shows seasonal as well as inter-annual variations. This study uses the inter-annual average of both the storage requirement scheme and the MSWV cycle as signatures of the best temporal equilibrium that is achievable in a given resource/demand context (the climatological equilibrium). For a simplified water resource system in a French mountainous region, we characterize how and why these signatures change should the climate and/or the demand change, mainly if changes are projected in the mean regional temperature (increase) and/or precipitation (decrease) as well as in the water demand for energy production and/or maintenance of a minimum reservoir level.

Results show that the temporal equilibrium between water resource and demand either improves or degrades depending on the considered future scenario. In all scenarios, the seasonality of MSWV changes when, for example, earlier water storage is required to efficiently satisfy increasing summer water demand. Finally, understanding how MSWV signatures change helps to understand changes in the storage requirement scheme.
\end{abstract}

\section{Introduction}

Mountain catchments yield most of the European hydroelectric production (Eurelectric gives ca. 140 TWh for Scandinavia and the Alps and refers to the "blue battery" of Europe). At high elevation (and/or latitude), spatial and temporal variations of the snowpack make the hydrological regime of rivers highly seasonal with low and high flows in the snow-accumulation and snowmelt seasons respectively. On the other hand, the electricity demand is also highly seasonal, with consumption peaks that mainly occur during the winter (e.g. Schaefli et al., 2007). The temporal deviations between the resource and the demand can be balanced with storage and release operations, transferring the resource in excess at a given time to times when it is insufficient. Most water storage reservoirs in Europe were designed and are managed to balance these two seasonal signals. Many of these reservoirs are not only dedicated to hydroelectricity production but are assigned other management objectives, related for instance to low flow maintenance, irrigation and drinking water supply (Loucks et al., 2005). In multi-purpose configurations, the time profile of the day-to-day storage levels resulting from storage and release operations aims at the best possible socio-economic equilibrium between water inflows and water demands. This optimal storage requirement scheme (for conciseness also denoted as storage scheme) is thus a signature of the best temporal equilibrium between the natural resource and the demand under a given climate, which we call climatological equilibrium.

Significant regional changes are expected worldwide for the next decades as a result of climate change. This will be especially the case for the hydrological regime of mountain 
rivers. Warmer temperatures are expected to reduce the ratio of snow to rainfall and shorten the snow accumulation period. The spring snowmelt is expected to reduce and to shift earlier in the year by two weeks to one month (Schneider et al., 2013; Lafaysse et al., 2014). Warmer temperatures are also expected to increase the demand for irrigation water (Rosenberg et al., 2003; Rosenzweig et al., 2004) and to modify the seasonal pattern of electricity demand, with lower consumption for heating during the winter and greater needs for cooling during the summer (Alcamo et al., 2007; Hekkenberg et al., 2009). As a result, climate change is expected to modify the seasonal equilibrium between water availability and demand (Raje and Mujumdar, 2010).

A number of recent studies have explored the potential impact of climate change on water systems (e.g. Gaudard et al., 2013). They are mostly based on the simulation of the management system over future periods and the statistical analysis of simulation outputs in terms of system performance. The simulation is classically based on day-to-day system operation scenarios obtained with either simple management models, based on rule curves or balance equations (Veijalainen et al., 2010; Ashofteh et al., 2013), or more sophisticated models mimicking a real operational context (e.g. Minville et al., 2009; Raje and Mujumdar, 2010; Vicuña et al., 2010). System performance is estimated using synthetic criteria such as the mean benefit from hydropower or agricultural production or the RRV criteria (Reliability, Resilience, and Vulnerability), a statistics of system failures such as dayto-day deviations between the effective supply and the demand (Hashimoto et al., 1982; Moy et al., 1986). Interpreting those performance criteria is not an easy task since (i) they may combine resource and demand modifications together with management adaptability issues and (ii) they summarize behind a single value quite complicated time patterns - namely, they cannot inform whether the tested management rules have to be modified or whether any better rules exist, nor can they describe the possible modification of the temporal resource/demand equilibrium over the considered period, even though understanding the time patterns behind such modification is likely to highlight the reasons for change in the system performance.

In the present work, we use the mean inter-annual pattern of the storage requirement as a first signature of the evolution of the climatological resource/demand equilibrium. We also consider the marginal value of storage water (MSWV) representing the future benefit that would be obtained at any given time from an additional unit of water volume stored in the reservoir. We estimate it as a by-product of deterministic dynamic programming (Masse, 1946; Bellman, 1957). The variations of MSWV with time for different levels in the reservoir drive the day-to-day storage scheme required to maximize a chosen benefit function coupling water inflows, demand and constraints. They provide a quite detailed description of the role played by the reservoir in redistributing the water throughout the year and from one year to another given the constraints. We propose the mean interannual pattern of MSWV as an alternative signature of the resource/demand disequilibrium. We also look at how these signatures are modified by changes in climate or demand. We compute both signatures under the present climate and a set of future climate scenarios, for a simplified water resource system with a single storage reservoir. This system is a catchment located in the Southern French Alps. We analyse the signature sensitivity to a mean regional temperature increase, a precipitation decrease and both together. We also explore the influence of the nature of water demand on both signatures (energy production and water level maintenance).

The paper is organized as follows. Section 2 briefly describes how the MSWV are estimated and how they are used for the determination of the storage scheme. Section 3 presents the simplified water resource system, the data and the simulation models considered in the application to the Upper Durance River (France). It also describes the future climate scenarios considered in this work. The storage scheme of this system is presented and discussed in Sect. 4. The inter-annual pattern of MSWV through the calendar year for the present and future climates are presented and discussed in Sects. 5 and 6, when they are interpreted as signatures of the climate change. Section 7 presents the conclusions.

\section{Storage water values and storage requirement scheme}

The optimal storage requirement scheme is the day-to-day storage level required over the analysis period $\left[t_{0}, t_{N}\right]$ to reach the best possible equilibrium between water resource and demand, given operational constraints. This scheme maximizes over the period the sum of the benefits at each time step $t_{i}$ of the analysis period, plus the benefit expected from the water remaining in the reservoir at the end of the period. The benefit function for any time step, further referred to as the "current" benefit function, can be expressed as a weighted sum of the benefits and costs over different water uses or management objectives. This function thus reads as

$g\left(u_{t_{i}}, s_{t_{i}}, t_{i}\right)=\sum_{j} c_{j} g_{j}\left(u_{t_{i}}, s_{t_{i}}, t_{i}\right)$,

where $g_{j}$ is a function representing the monetary benefits and costs associated with the different services by operation $u_{t_{i}}$ at the storage level $s_{t_{i}}$ during $\left[t_{i}, t_{i+1}\right]$ and $c_{j}$ is a weighting constant defined according to the priority level assigned to use $j$.

For each time step $t_{i}$, an immediate use of water reduces the availability of stored water for all future water uses. The current benefits must therefore be balanced against losses in future benefits. Identifying the optimal storage variation at the current time step requires knowing the marginal value of storage water (MSWV) in the reservoir from the current 


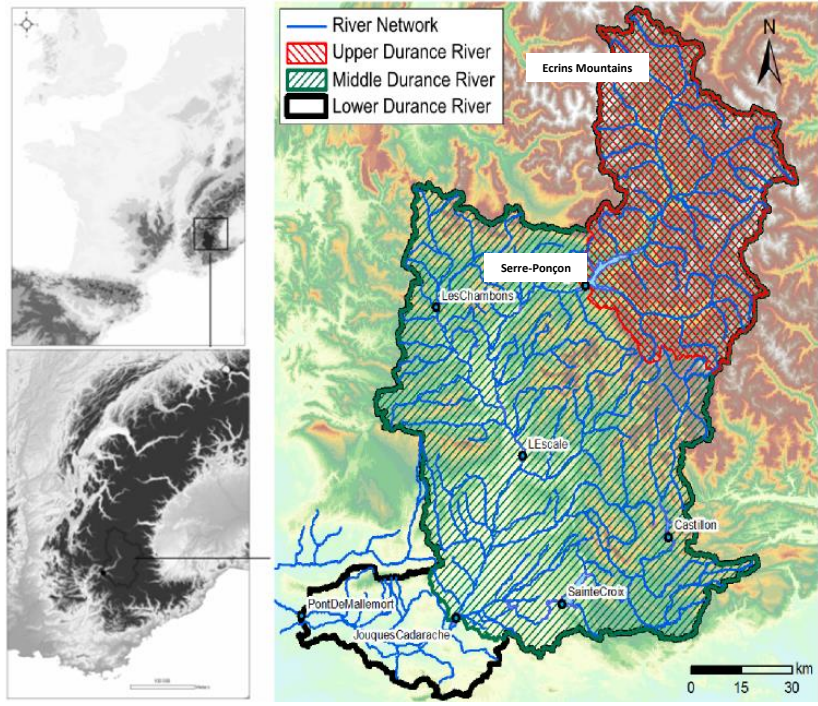

Figure 1. Map of the Durance River watershed. Serre-Ponçon reservoir is the outlet of the Upper Durance River watershed.

time step to the next. MSWV estimation is detailed within Appendix A.

As shown in Appendix A and discussed below, the MSWV is time and storage level dependent. It can be obtained a posteriori as a by-product of deterministic dynamic programming, an optimization method developed for multistage dynamic decision processes. In our case, MSWV values are estimated for the whole analysis period at a daily time step for 51 storage levels uniformly distributed between the minimum and maximum storage bounds $s_{\min }$ and $s_{\max }$. At any given day, these MSWV can be used in a second optimization stage to identify the optimal storage variation given the current water storage in the reservoir. For a given storage level at the beginning of the analysis period, the forward day-today optimization process therefore gives the optimal storage requirement scheme for the whole analysis period.

In the following, the MSWV is expressed in relative value units per cubic metre denoted as $\mathrm{SWV} \mathrm{m}^{-3}$.

\section{Case study and data}

\subsection{Catchment characteristics and experimental setup}

The Upper Durance River (UDR) basin at Serre-Ponçon is a meso-scale basin $\left(3580 \mathrm{~km}^{2}\right)$ located in the southern French Alps (Fig. 1). Its outlet is the Serre-Ponçon reservoir, a storage reservoir that is part of a large hydroelectric system operated by Electricité de France (EDF). It plays a key role in the energy supply of the Provence region, which extends from the Alps to the Mediterranean shore. This region, which is connected to the rest of the French electric network by a unique line, is limited in terms of energy imports. SerrePonçon reservoir objectives and constraints are also related to recreational activities on the lake, drinking and irrigation water supply and to the preservation of downstream ecological integrity. Contrary to most French mountain basins of this size, there are no significant reservoirs built along the UDR and its discharges are thus almost natural. The local climate is much drier than in the northern French Alps (Durand et al., 2009) due to the Mediterranean influence and to the protection from oceanic disturbances provided by the high Ecrins Mountains (Fig. 1). With elevations ranging from 700 to $4100 \mathrm{~m}$ a.s.l., the catchment presents highly seasonal flows due to snow accumulation and melt. Winter low flows can last 3 months or more. Long low flow sequences are also frequently observed in late summer and fall. During these seasons and when the precipitations are negligible, such a low flow episode can last several weeks after the end of the snowcovered period. Major floods are often observed in fall with intense rainfall events (Lafaysse et al., 2011).

We consider a simplified water resource system inspired by the real UDR system with two basic uses: hydroelectric production (HEP) and maintenance of a minimum water level in the reservoir lake during the summer season for recreational activities (Reservoir Level Maintenance denoted as RLM). We chose HEP and RLM because these two objectives present important differences in terms of adequacy with the water resource availability and are important for the real system of Serre-Ponçon.

The benefit function used in Eq. (1) for the determination of MSWV is the sum of the possible benefits from HEP as defined by Eq. (2) and benefits from RLM during a summer season as defined by Eq. (3):

$g_{\mathrm{HEP}}\left(u_{t_{i}}, s_{t_{i}}, t\right)=\operatorname{HEPI}_{t_{i}} u_{t_{i}} r\left(s_{t_{i}}\right)$,

where $u_{t_{i}}$ in $\mathrm{m}^{3} \mathrm{~s}^{-1}$ is the discharge released from the reservoir for HEP, HEPI is the daily interest of HEP in value units $\mathrm{kWh}^{-1}$ (see Sect. 3.4) and $r$ is the hydropower production coefficient in $\mathrm{kWh} \mathrm{m}^{-3}$ which depends on the water head in the reservoir:

$$
\left\{\begin{array}{l}
g_{\mathrm{RLM}}\left(s_{t_{i}}, t_{i}\right)=K\left[1-b\left\{\max \left(s^{*}-s_{t_{i}}, 0\right)\right\}^{2}\right] \\
\quad \text { if } t_{i} \in \text { summer season } \\
g_{\mathrm{RLM}}\left(s_{t_{i}}, t_{i}\right)=0 \text { if not }
\end{array}\right.
$$

In Eq. (3), $K$ is the maximal value of daily benefit (value units) that can be obtained during the summer period. It is achieved as soon as the storage is greater than a threshold $s^{*}=85 \%$ of the storage capacity, the volume below which recreational activities are expected to be reduced. The corresponding decrease in RLM benefit is assumed to be a quadratic function of the difference between the actual water storage and $s^{*}$. In Eq. (1), the values of the weighting parameters $c_{j}$ are referred to as $c_{\mathrm{HEP}}$ and $c_{\mathrm{RLM}}$ for the HEP and RLM objectives respectively and set either to 1 when the objective is considered or to 0 when it is not.

In the water balance of the reservoir, the only input and output discharges are respectively the inflow from the 
upstream UDR basin and the optimized water release. Direct precipitations to the reservoir and evaporation from the reservoir are neglected. Their inter-annual means are actually of the same order, and the net balance between both terms is less than $1 \%$ of the mean river discharge into the reservoir (Vachala, 2008).

In France, like in many countries where hydropower is not dominant, hydroelectric production is used to replace more expensive power generation facilities and the objective is to minimize the expected sum of other energy production costs for the national network as a whole. In this study, we consider a simplified daily interest of HEP estimated from a local daily temperature index (see Sect. 3.3) and the benefits are optimized for the system independently from other considerations of the energy production costs. In addition, summer RLM is a priority objective: an empirical guideline curve is used for reservoir operations (applied mostly in the spring season) and HEP optimization roughly applies to the water inflows that are not needed to satisfy the RLM objective.

However, it is expected that an increase of future energy costs will increase the interest of HEP and, as a consequence, benefits from recreational activities will be balanced with respect to benefits from HEP (or with respect to the reduction of other production costs allowed by the use of HEP). In this study, a benefit function (Eq. 3) is therefore used for RLM instead of a rule curve. This provides a rough estimate of the marginal value of storage water to satisfy the RLM objective. Recreational benefits are expressed as a function of water storage in the reservoir, similarly to Ward et al. (1996). However, our formulation does not include information about tourist affluence due to the lack of appropriate data in the region. The value of $K$ in Eq. (3) is chosen so that the maximum benefit obtained from RLM is of the same order of magnitude as the one obtained from HEP, if they were considered separately. This makes it possible to analyse a double-objective configuration with objectives of equivalent economic value, a situation that could occur in the future.

The inflows to the reservoir are modelled with CEQUEAU (Morin et al., 1975), a semi-distributed hydrological model already applied by EDF for previous climate change impact studies on different mesoscale French basins. Snow accumulation and melt, effective rainfall, infiltration and evapotranspiration fluxes are estimated for each of the 99 subbasins from daily series of mean areal precipitation and surface air temperature. The discharges produced by all hydrological units are routed through the river network to produce the total water inflow into the reservoir. The CEQUEAU model of UDR has been calibrated and validated by Bourqui et al. (2011) with a split sample test procedure. The NashSutcliffe efficiency criterion (Nash and Sutcliffe, 1970) is 0.86 for the 1981-2005 calibration period and 0.83 for the 1959-1981 validation period.

\subsection{Climate scenarios}

The observed precipitation and temperature data for the 1970-1999 control period are obtained from the daily meteorological reanalyses developed by Gottardi et al. (2012) for French mountainous regions. The reference discharges to the reservoir for the control period are those obtained from CEQUEAU simulations.

The local-scale time series of temperature and precipitation for the future climate period 2070-2099 are obtained by perturbing the observed time series of the control period in a similar way to Horton et al. (2006). Six synthetic regional climate change scenarios are defined as an absolute change of the mean annual temperature and as a relative change of the mean annual precipitation. The magnitude of these changes is derived from a suite of climate modelling experiments conducted in the EU PRUDENCE project (Christensen, 2004) for SRES scenario A2 (Nakicenovic et al., 2001). It roughly corresponds to the 50th and 90th percentiles of changes estimated by the climate model experiments, representing respectively a 10 and $20 \%$ decrease in precipitation and a 3 and $5{ }^{\circ} \mathrm{C}$ increase in temperature.

Control and future hydrological regimes obtained from CEQUEAU simulations for these scenarios are presented in Fig. 2. A temperature increase leads to reduced snow accumulation in winter and an earlier melting season. This in turn induces a higher winter low flow and a lower snowmelt flood peak (Fig. 2, left). The snowmelt flood peak shifts by one month for the warmest scenario $\left(+5^{\circ} \mathrm{C}\right)$. Besides this change in flow seasonality, an increase in temperature also leads to a slight reduction of the mean annual inflow to the reservoir due to increased evapotranspiration losses in summer (up to $22 \%$ for the $+5^{\circ} \mathrm{C}$ scenario). Without temperature change, precipitation change scenarios modify the magnitude of the hydrological cycle (Fig. 2, middle). The mean inter-annual daily discharges decrease with the mean inter-annual precipitation, except for the winter period during which flows are sustained by deep underground storage. The large decrease of the snowmelt flood peak is the result of a smaller snowpack extent and thickness, induced by less winter to spring solid precipitation.

Scenarios with both precipitation and temperature changes lead to a modification of the hydrological regime that roughly combines the modifications previously discussed for temperature change (mainly modification in seasonality) or precipitation change alone (mainly modification in mean discharge).

\subsection{Economic interest of hydroelectric production}

A detailed representation of electricity prices is difficult to simulate because of the complex interaction with other energy production means and the high variability of the energy market. However, electricity prices in France tend to be higher for periods of high electricity consumption. Moreover, electricity consumption is higher during the cold season 

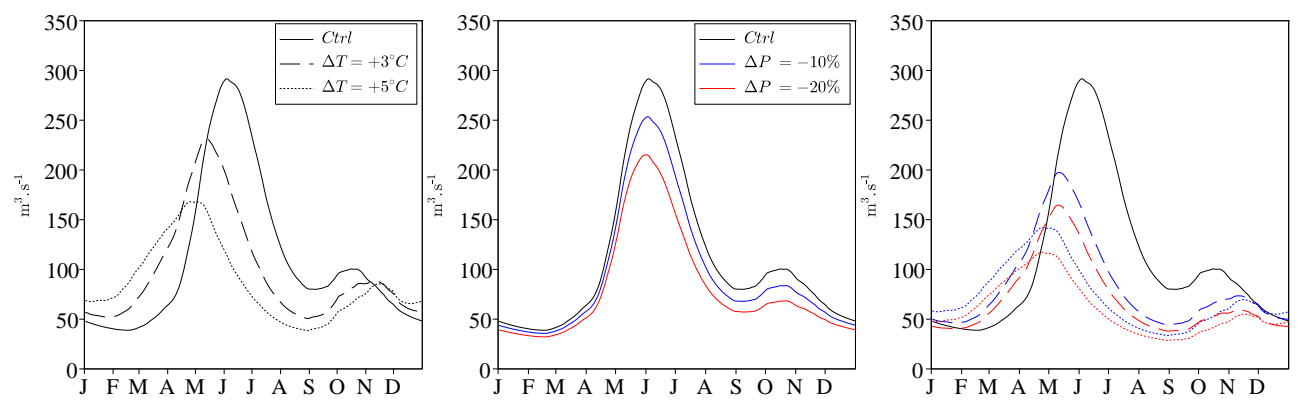

Figure 2. Mean inter-annual cycles of daily inflow to the reservoir for control data (black curve in all graphics, period 1970-1999) and two future meteorological scenarios (with prescribed changes of the mean annual temperature $(\Delta T)$ and precipitation $(\Delta P)$ over the period 2070 2099). Left: changes in mean annual temperature only. Middle: changes in mean annual precipitation only. Right: changes in both annual precipitation and temperature. The control hydrological regime is obtained from CEQUEAU simulations with the observed meteorological times series of the 1970-1999 period.

and highly correlated with the daily time variations of regional temperatures below an approximate heating threshold $T_{\text {heat }}=15^{\circ} \mathrm{C}$ that governs heating demand. As a result, a convenient formulation for the daily interest of HEP (HEPI) can be based on daily regional temperatures (Paiva et al., 2010). The electricity consumption is assumed to linearly decrease with the temperature up to a given threshold and to remain constant above this threshold.

In a future climate with higher summer temperatures, an additional demand for hydroelectric production is expected for cooling purposes. The daily HEPI expected in the future during the hot season is assumed to linearly depend on regional temperatures above a cooling threshold $T_{\text {cool }}=25^{\circ} \mathrm{C}$ (Buzoianu et al., 2005). In the following, the daily HEPI is therefore defined as a piece-wise linear function of daily temperature:

$$
\left\{\begin{array}{l}
\mathrm{HEPI}_{t_{i}}=\mathrm{HEPI}_{0}+\mathrm{HEPI}_{\mathrm{h} .}\left(T_{\text {heat }}-T_{t_{i}}\right) \text { if } T_{t_{i}}<T_{\text {heat }} \\
\mathrm{HEPI}_{t_{i}}=\mathrm{HEPI}_{0} \text { if } T_{\text {heat }}<T_{t_{i}}<T_{\text {cool }} \\
\mathrm{HEPI}_{t_{i}}=\mathrm{HEPI}_{0}+\mathrm{HEPI}_{\mathrm{c}} \cdot\left(T_{t_{i}}-T_{\text {cool }}\right) \text { if } T_{t_{i}}>T_{\text {cool }},
\end{array}\right.
$$

where $\mathrm{HEPI}_{0}$ is the HEPI when temperatures are in between cooling and heating temperature thresholds, and $\mathrm{HEPI}_{h}$ and HEPI $_{c}$ are the additional HEPI rates for each the heating and the cooling seasons respectively. The HEPI is expressed in value units per $\mathrm{kWh}$ denoted $V$ hereafter. $\mathrm{HEPI}_{0}$ and $\mathrm{HEPI}_{\mathrm{h}}$ are set to unity $\left(=1 \mathrm{~V}^{\circ} \mathrm{C}^{-1}\right)$ in accordance to Paiva et al. (2010). A higher value was set for $\mathrm{HEPI}_{\mathrm{c}}$ $\left(\mathrm{HEPI}_{\mathrm{c}}=2.5 \mathrm{~V}^{\circ} \mathrm{C}^{-1}\right)$.

Time series of daily HEPI were obtained for each scenario of daily temperatures. The corresponding mean inter-annual values of daily HEPI are presented in Fig. 3 as characteristic seasonal HEPI patterns.

\section{Storage signature}

In order to briefly illustrate the kind of climate signature proposed in this work, we start the analysis of our results looking at the storage scheme obtained for the period 1970-1999

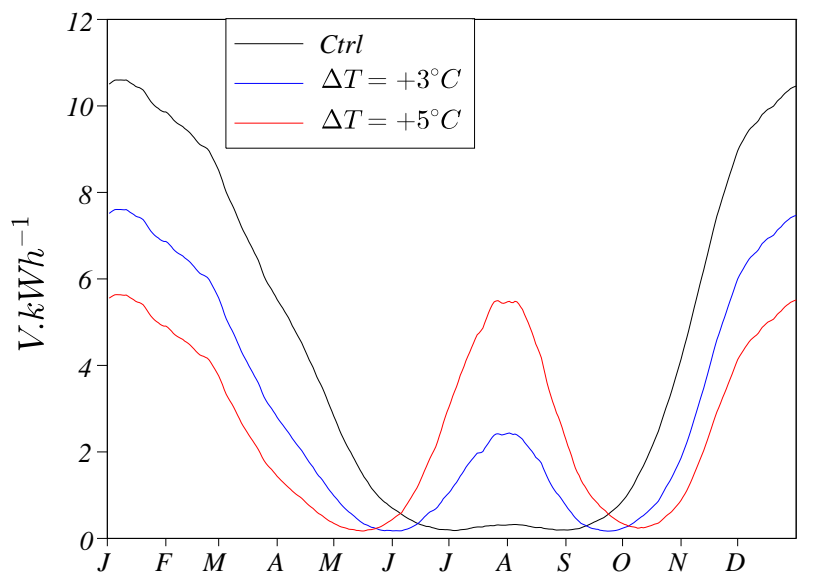

Figure 3. Mean inter-annual cycles of the interest hydroelectric production (HEPI) for the control period and two different future scenarios of annual temperature increase $\Delta T$.

when both HEP and RLM objectives are taken into account (this configuration is denoted HEP + RLM in the following). The reservoir inflows and HEPI scenarios are produced as described in Sect. 3. Their optimal temporal balance is computed through dynamic programming as explained in Sect. 2. The constrained summer season for RLM runs from 15 June to 31 August and the minimum assigned storage level is $s^{*}=85 \%$ of $s_{\max }$ during this period, and $s^{*}=0$ outside this period. As shown Fig. 4, the storage scheme presents a significant seasonality. The storage level continuously decreases during winter months, when HEPI is high and inflows are low. It then increases during spring-time with high spring snowmelt inflows and lower HEPI values. The inter-annual variability of the storage scheme is moderate (see dispersion between grey curves around the mean inter-annual pattern in Fig. 4), and much lower than the intra-annual variability that covers the full capacity range from 10 to $100 \%$. The lowest inter-annual variability of the scheme is obtained for the first days of November. Each year, the reservoir is roughly full at 


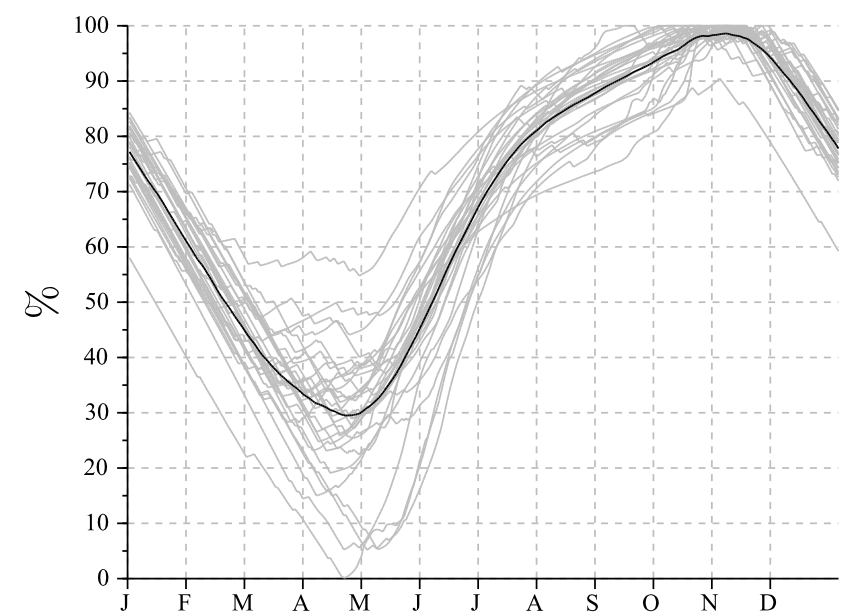

Figure 4. Storage requirement scheme for the period 19701999 (configuration HEP + RLM). Grey curves: day-to-day storage level trajectory required each year to reach the best possible resource/demand equilibrium, given the constraints; Black curve: mean inter-annual storage cycle.

this period. The highest inter-annual variability of the scheme is during spring period when storage levels vary from 10 to $60 \%$ of the reservoir capacity. All storage curves converge next rapidly to a high storage level as required by the summer touristic level objective. Despite this, the summer level objective (i.e. $85 \%$ of $s_{\max }$ ) is never reached on time (i.e. the 15 June) but roughly one month later.

In the following sections, because the temporal variations of the storage scheme are mainly seasonal, we use its mean inter-annual pattern as a first signature of the disequilibrium between water resources and demand for the studied climatic and economical forcing. For brevity, we call this the storage signature.

\section{Storage water value signature}

The storage signature derives from temporal patterns of MSWV that we discuss now for various climate scenarios and various combinations of objectives. For a more comprehensive analysis, we consider in a preliminary step two objectives separately (HEP or RLM) and subsequently a double-objective configuration (HEP + RLM).

\subsection{Hydroelectric production}

The optimization of the HEP objective alone corresponds to $C_{\mathrm{HEP}}=1$ and $C_{\mathrm{RLM}}=0$ in Eq. (1). Note first that the efficiency of the hydroelectric production system is an increasing function of water head in the reservoir. If HEPI were constant throughout the year, the storage scheme would be to maintain the water level at its highest possible value, which may be a bit lower than the storage capacity in order to avoid future spillage (see for example Turgeon, 2007). Except be- fore large inflow periods such as the snowmelt season, this scheme would correspond to high MSWV for most reservoir levels, especially the lowest ones. In the studied configuration, MSWV is higher during the periods prior to the highest HEPI. The high seasonality of HEPI (Fig. 3) thus influences the seasonality of MSWV and modulates the storage scheme.

Figure 5 illustrates the variation of the HEPI and the water inflows to the reservoir with time over a 4-year period (1 January 1977 to 1 January 1981). It also presents the corresponding variations of the MSWV with time for different reservoir levels (corresponding to 10,50 and $90 \%$ of storage capacity) and the resulting optimal storage requirement scheme.

At any time, MSWV is lower at high storage levels (Fig. 5, top). At these levels, the increase of the future benefit related to an additional storage of water is very low. Indeed, additional stored water might be turbined during very low HEPI periods only, in order to avoid un-valorized spillages. At any storage level, MSWV fluctuates in time. At high storage levels (e.g. $90 \%$ ), MSWV is low except when a very high HEPI period is imminent (e.g. before winter periods). At low storage levels (e.g. $10 \%$ ), MSWV is conversely high to very high (up to 10 relative value units) except when a very high flow period is imminent (e.g. before spring flood periods). At all storage levels high MSWV prompts water storage for future use.

Periods of high HEPI alternate with periods of inflow discharge (Fig. 5, bottom). As a result, MSWV presents high seasonal variations for all reservoir levels (Fig. 5, top). During the late winter and early spring transition periods, the concomitant decrease of HEPI and rapid increase of snowmelt inflow diminishes the storage requirement. The following increase of MSWV is quite abrupt, as can be seen during the year 1979 in June for the storage level $50 \%$ and in September for the storage level $90 \%$. It begins as soon as spillage is no longer required, given the known future inflows.

For any given storage level, MSWV varies with time reflecting the role of the reservoir in adjusting the adequacy between the future HEPI and the future availability of water from upstream catchment. Future resource abundance (respectively scarcity) decreases (respectively increases) the value of more storage water - like for example in May 1977 (respectively September 1977).

In addition to a marked seasonality, MSWV shows yearto-year variations related to the future ratio of HEPI and the inflow. MSWV is for instance higher in 1980 than in the previous 3 years. This inter-annual variability directly translates to the storage requirement scheme with a spring storage higher than $30 \%$ of the capacity for 1980 whereas it roughly equals zero for previous years.

As for the storage requirement scheme, the variation of the MSWV in time reflects in a sophisticated way the temporal patterns of the climate variables governing the water demands and inflows. In the following sections we will use 

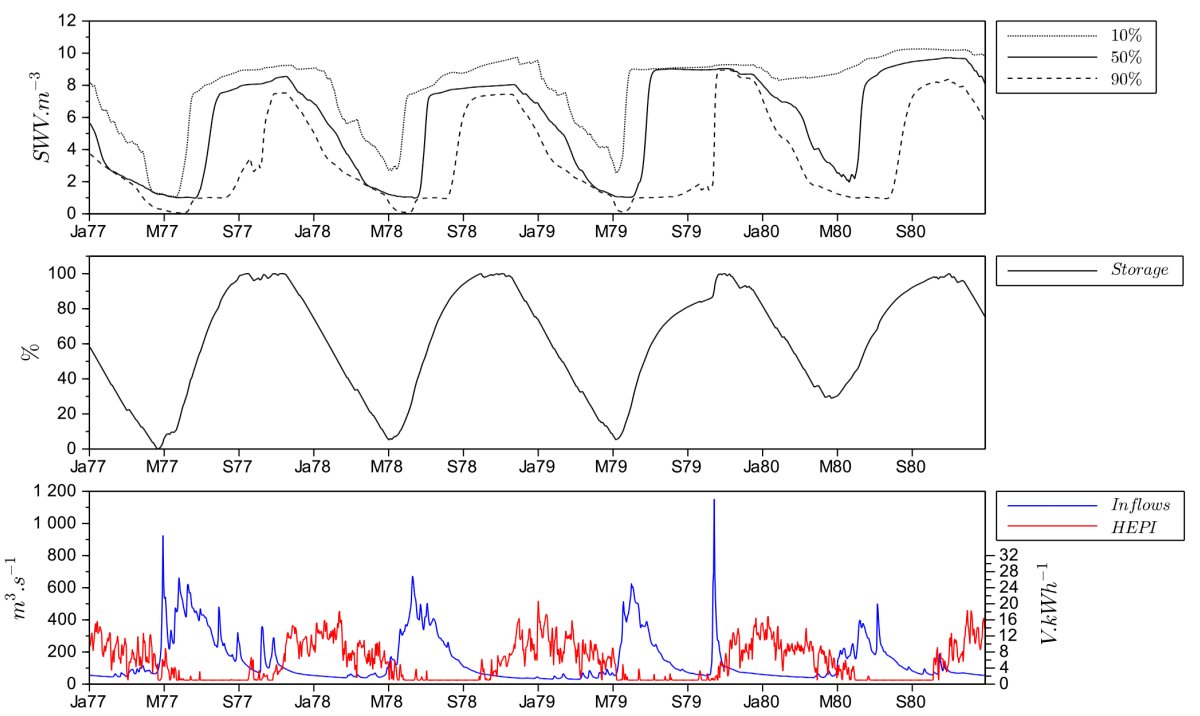

Figure 5. Variations of MSWV, reservoir level, inflows and interest for hydroelectric production (HEPI) from January 1977 to January 1981 for the meteorological control scenario (Ja: January, M: May, S: September). Top: marginal value of water $\left(\mathrm{SWV} \mathrm{m}^{-3}\right)$ for different reservoir storage levels corresponding to 10, 50 and $90 \%$ of the capacity. Middle: reservoir level (\%) Bottom: water inflow to the reservoir (blue curve, $\mathrm{m}^{3} \mathrm{~s}^{-1}$ ) and interest of hydroelectric production (red curve, $\mathrm{V} \mathrm{kWh}^{-1}$ ).

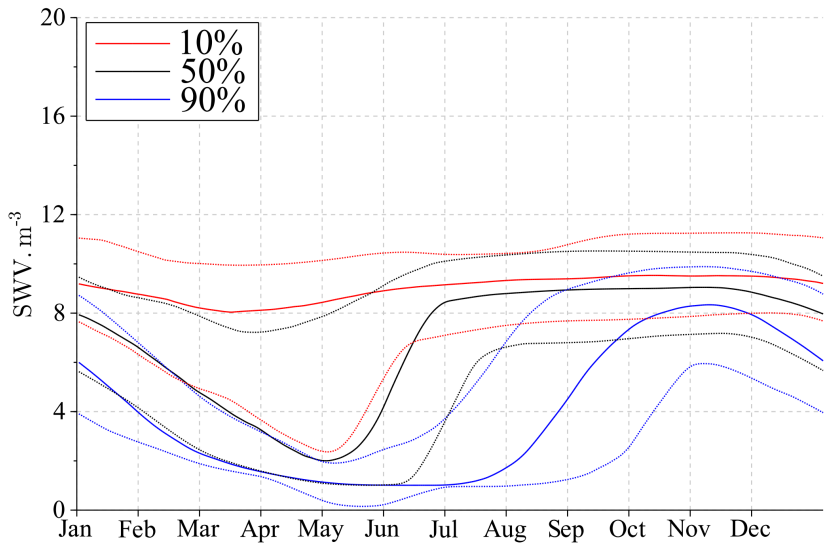

Figure 6. MSWV signature for the single hydroelectric production objective (HEP). The mean inter-annual MSWV variation obtained for the 1970-1999 period is plotted for three reservoir storage levels (10, 50 and $90 \%$ of storage capacity). For each storage level, the upper, middle, and lower curves correspond respectively to the 95th percentile, the mean and the 5th percentile of MSWV calendar values obtained for the 30 years of the period.

the mean inter-annual patterns of MSWV for different reservoir levels as a second signature of the disequilibrium between water resource and demand under climatic and economic conditions. The MSWV signature obtained for the UDR system is presented in Fig. 6 for three storage levels $(10,50$ and $90 \%$ of storage capacity). In addition to the mean inter-annual value, Fig. 6 also shows the 5th or 95th percentiles of the MSWV calendar values. For the sake of conciseness, the expression "MSWV signature" will subsequently be used for this type of graph.

\subsection{Summer reservoir level maintenance}

We now consider a system for which the only objective would be to maintain a minimum water level in the reservoir during the summer months as explained in Sect. 3 (i.e. $C_{\mathrm{HEP}}=0$ and $C_{\mathrm{RLM}}=1$ in Eq. 1 ). Penalty costs are incurred in the event of failure to maintain the required level. The MSWV corresponds to the additional reduction of penalty costs that would be achieved by storing one more cubic metre of water at the current date. The MSWV signature is quite different from the one obtained for the HEP objective alone although it presents also a marked seasonality (see Fig. 7 compared to Fig. 6).

The possibility to achieve the objective depends on the current storage level and on the volume of inflow to the reservoir from the current date to the beginning of the next constrained period. At a given date, the higher the current storage level, the easier it is to achieve the objective.

For a given storage level, the longer the duration until the next constrained period, the larger the total future inflows to the reservoir and the easier it is to reach the objective. MSWV therefore slowly increases over the year to reach a maximum in early summer. According to Fig. 7 the MSWV maximum is nearly 1 month before the beginning of the constrained period for the most adverse situations (95th percentile envelope curve - corresponding to the driest spring years) or as late as mid-July for the most favourable situations (5th percentile envelope curve - corresponding to the wettest spring years). The lowest MSWV is zero, indicating that there is no interest to store water as forthcoming inflows will fill the reservoir to the required level on time (Fig. 7). 


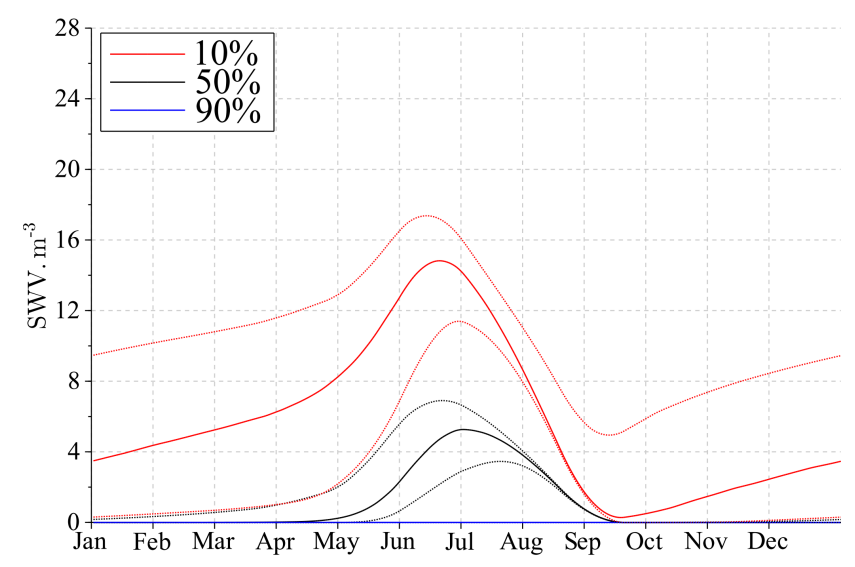

Figure 7. MSWV signature for the reservoir level maintenance objective (RLM). See Fig. 6 caption for details. The $90 \%$ curves are confounded with the $x$-axis.

This is the case for almost all reservoir levels in September, after the end of the constrained period (an exception is for the driest years if the storage level is low). This applies also from mid-September to mid-April at more than $50 \%$ of the storage capacity, when large inflows from the spring snowmelt flood are expected. In terms of seasonality the periods of high and low MSWV are roughly in phase opposition with those obtained previously for the HEP objective.

\subsection{Double-objective configuration}

Figure 8 presents the MSWV signature obtained when both HEP and RLM objectives must be fulfilled (i.e. $C_{\mathrm{HEP}}=1$ and $C_{\mathrm{RLM}}=1$ in Eq. 1). The storage signature for this configuration is the one discussed in Sect. 4 (Fig. 4).

For this configuration, MSWV is logically higher than those obtained for each single-objective configuration (Figs. 6 and 7). It is actually not possible to produce as much HEP and to fulfil the RLM objective as well as in the singleobjective configurations. To limit the cost of RLM failure, water allocations previously determined for the single HEP objective configuration must be re-allocated to periods with lower HEPI thanks to higher MSWV at all reservoir levels, since high MSWV reduces the interest of immediate water use.

The MSWV signature for the double-objective configuration is not exactly an additive combination of the two single-objective signatures owing to the non-linearity of the optimization. The most significant difference between the HEP + RLM signature and the sum of the single-objective ones is during the winter season at low reservoir levels. The higher MSWV obtained for the double-objective configuration directly translates to the storage scheme. For instance, the minimum storage levels of the storage scheme are all greater than $10 \%$ (see Fig. 4) whereas it can reach zero in the single HEP objective configuration (see spring storage level

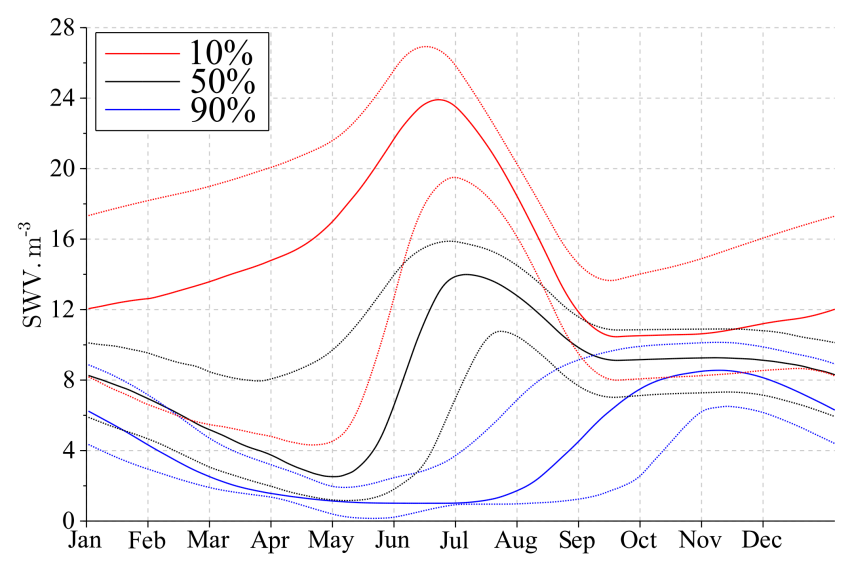

Figure 8. MSWV signature for the double-objective configuration (HEP + RLM). See Fig. 6 caption for details.

for the year 1977 in Fig. 5). Similarly, the storage level in the early fall is always over $80-90 \%$ in the double-objective configuration, whereas it may be lower than $80 \%$ in the single HEP objective configuration (see year 1979 in Fig. 5).

In summary, the MSWV signature displays patterns of increasing complexity when the variety of assigned objectives increases. The seasonal shapes of the different objectives combine almost linearly and reflect with great detail the respective seasonality of the climate and the various demands.

\section{Sensitivity of the signatures to climate change}

We show now the sensitivity of the storage and MSWV signatures to a climate modification resulting from an annual temperature increase, an annual precipitation decrease and finally from both modifications simultaneously. This sensitivity analysis illustrates the interest of the presented results in terms of climate change signatures.

Figure 9 displays the storage signature for the doubleobjective configuration HEP + RLM. The signature is more sensitive to temperature warming than to precipitation decrease. For all scenarios, the average storage level increases and the magnitude of seasonal storage fluctuation is significantly lower which means that the resource-demand temporal equilibrium improves under the considered future climates. The temporal pattern of the storage signature is also modified: the late summer period for which high levels of storage were required is 2 months longer for a $3{ }^{\circ} \mathrm{C}$ warming. For the $5^{\circ} \mathrm{C}$ warming scenario, a bimodal pattern is obtained and the period with the highest required storage levels is shifted to early summer.

Figure 10 shows the dependence of MSWV signatures to temperature for HEP and RLM objectives. For the HEP objective alone (first row Fig. 10), a temperature increase modifies the seasonality of the MSWV signature but does not 


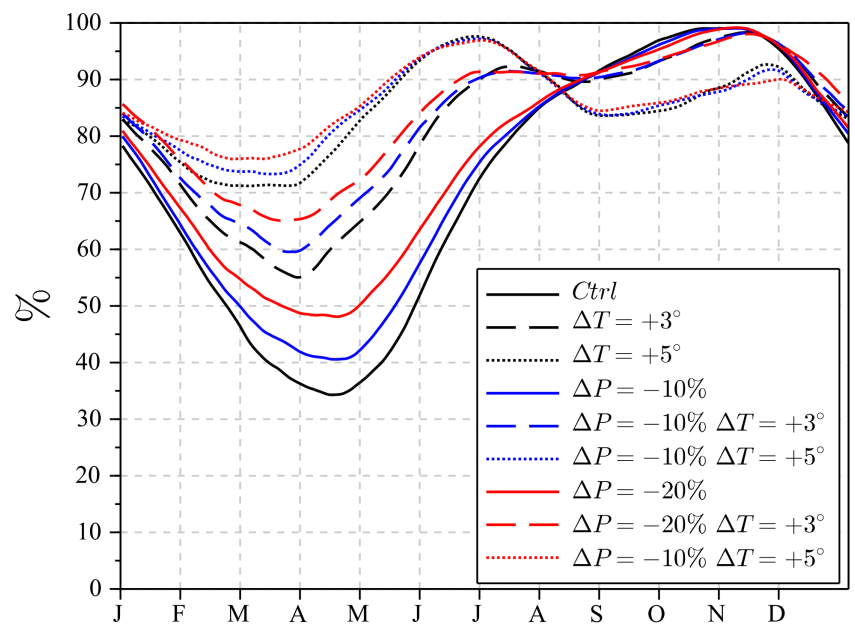

Figure 9. Sensitivity of storage requirement scheme to temperature increase or precipitation decrease or both together.

significantly change the average value of storage water. The MSWV seasonal peak is shifted from autumn to summer for high reservoir levels and disappears at low levels. At all levels the seasonality of MSWV is smoothed out; in particular for low and medium reservoir levels (10 and 50\%), MSWV becomes practically constant throughout the year. This observation corroborates the better temporal balance between resource and demand under a modified climate. At low and middle storage levels and compared to the control period, the increase of MSWV during the spring season is due to far less intense snowmelt floods (Fig. 2) and in turn to a large decrease of potential spillage risk. Potential spillage is also reduced because of a better temporal match between inflows and periods of high HEPI: for the control period, the main inflow period (spring) is almost 8 months before the highest HEPI (winter); for the increased-temperature scenarios, the snowmelt flood is up to 1 month earlier and a second period with high HEPI appears in the summer season only 3 to 4 months later. At high storage level, the MSWV signature modification is different but the reasons for these changes remain the same. The large MSWV values during the late spring and summer seasons increase the interest of raising the water head during this period without causing later spillage thanks to the new and greater interest of HEP in summer. The low MSWV values in winter result from the lower HEPI demand for this season.

For the RLM objective alone, lower mean inflow and earlier snowmelt increase MSWV earlier in the year for reservoir levels lower than the summer objective. The objective is therefore more difficult to meet on time than for the control period. For low reservoir storage levels the positive MSWV obtained in September even shows incapacity to meet this single objective.
Finally, the MSWV signature obtained for the double HEP + RLM configuration is approximately an additive combination of the two single-objective signatures, as for the present climate. For example, for the $50 \%$ storage level, the large MSWV decrease observed in the control climate during the 6 months from December to May tends to disappear as a consequence of the smaller snowmelt flood and the increased HEP interest during the summer months.

Regarding now a precipitation decrease, Fig. 11 displays the MSWV signature for the HEP + RLM configuration. As changes in precipitation do not influence the seasonality of the inflow (Fig. 2) and the demand, the seasonality of MSWV is maintained, whatever the reservoir level. The decrease in precipitation leads to a reduced mean inflow to the reservoir and, in turn, to an increased MSWV mean value at all storage levels and all seasons (excepted during the summer season for the $90 \%$ storage level where MSWV is zero). This means more severe conditions with a concentration of water allocations to HEP in the periods with the highest HEPI values. Similar results are obtained when considering HEP or RLM alone (not shown).

Finally, the MSWV signature resulting from a modification of both precipitation and temperature changes is shown for three storage levels in Fig. 12. Seasonality and mean value of MSWV are modified. Changes of MSWV for this combined change are approximately an additive combination of the partial ones, and directly translate to modifications of the storage scheme described previously. They lead for instance to building the storage earlier in order to better use the earlier spring snowmelt flood. They also lead to reducing the magnitude of storage fluctuations and thus to increase the water head, especially before the period of high HEPI in summer due to cooling needs.

\section{Conclusions}

In this study we formalized the central role of water storage management in balancing seasonal fluctuations of the water resource/demand equilibrium using an elementary optimization technique. The representation of the water system is reduced to a small set of objectives and free of any hypothesis on the constraints and uncertainties of the real-time management. Derived storage water values and reservoir levels exhibit seasonal patterns that we propose to read as signatures of this climatological equilibrium and its potential modification under changing hydro-climatic conditions. We consider such signatures as attractive alternatives to performance indicators like statistics of a system's failures in the sense that they preserve quite complicated seasonal patterns giving more insight into the socio-technical system behaviour.

The presented case study illustrates how the proposed signatures contain, under a synthetic set of graphs, much information on the seasonality of the governing processes and their eventual shifts in time. The multi-purpose system taken 

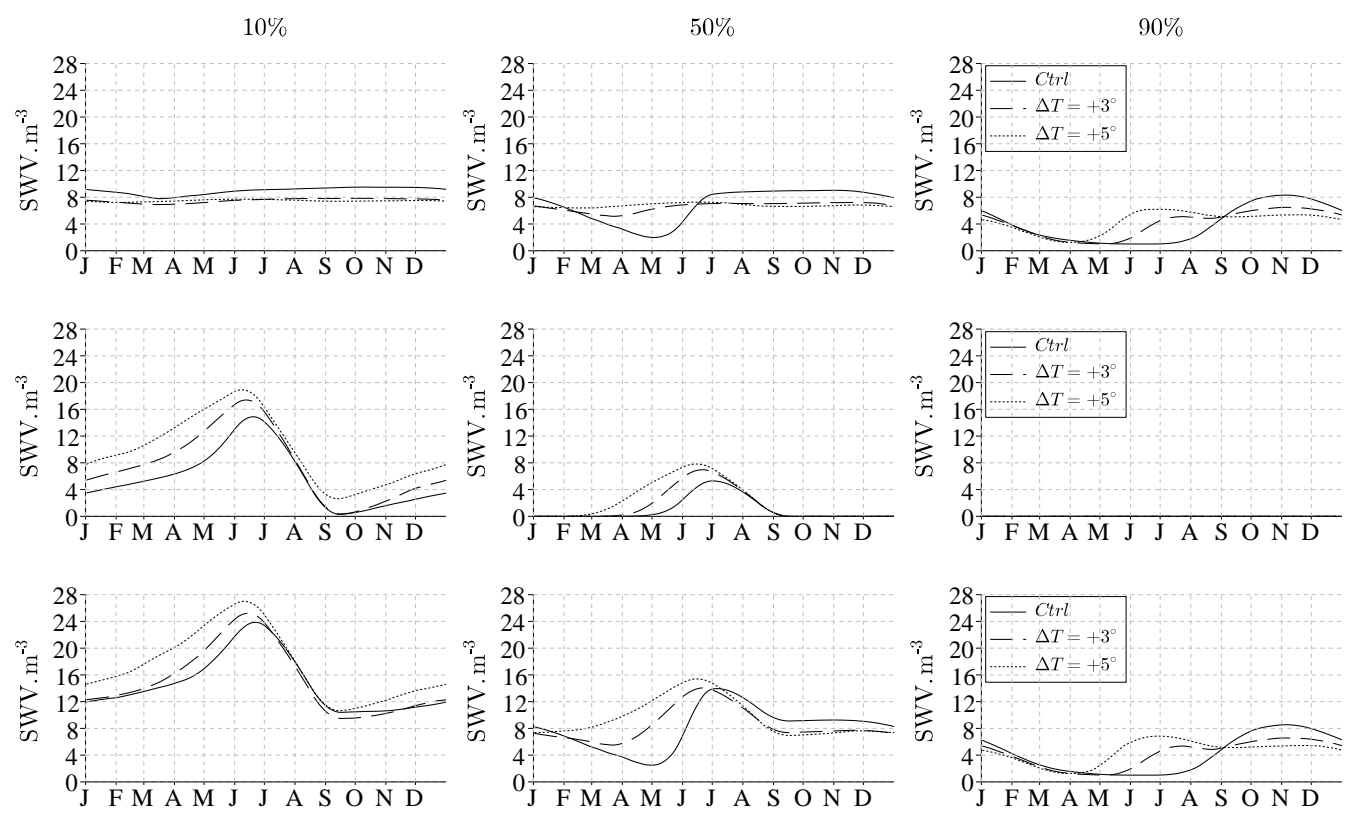

Figure 10. Sensitivity of MSWV signatures to temperature. The different curves correspond to the control data set and to two scenarios of warming. The different columns correspond to storage levels of $10 \%$ (left), $50 \%$ (middle) and $90 \%$ (right) of storage capacity. The objectives considered are the HEP (top graphs), the RLM (middle) and a combination of the two (bottom).
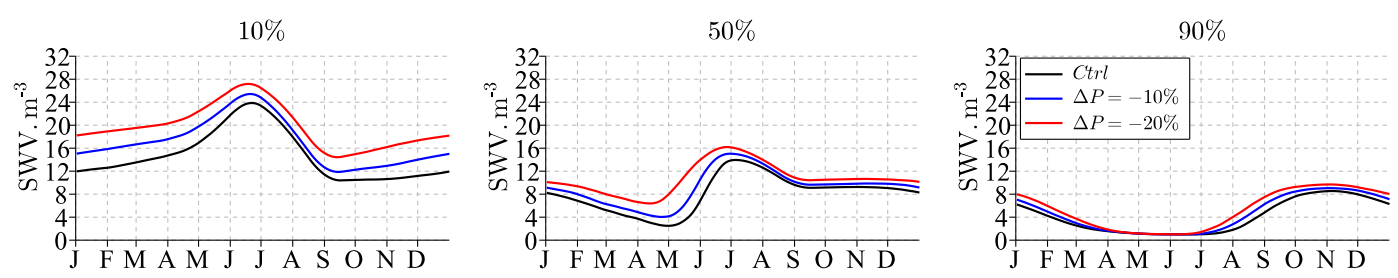

Figure 11. Sensitivity of MSWV signatures to precipitation changes in the case of the double-objective configuration (HEP + RLM). The different columns correspond to storage levels of $10 \%$ (left), $50 \%$ (middle) and $90 \%$ (right) of storage capacity.

in the French Alps is reduced to the management of a single reservoir responding to a demand for hydroelectricity and reservoir level maintenance during a touristic period in a climate change context. This case study led to the following considerations:

- When considering several management objectives, each individual objective signature sheds light on its specific role and the multi-purpose signature is not the mere linear combination of the individual signatures, which reveals the potentially non-linear interaction or competition between objectives.

- When analysing signatures one by one, the smoothness of their shape and their amplitude seems to be informative. Both for MSWV and storage signatures, a smoother shape shows a better seasonal fit between resource and demand and thus an easier manageability or lower storage fluctuation needs.
- When comparing signatures under different climatic conditions, changes in shape reveal changes of the governing processes. For instance, the studied water system seems to be more sensitive to warmer conditions than to drier ones. Warmer conditions deeply modify the different signatures (MSWV and storage) in relation with the behaviour of the snow-pack and the electricity demand. Drier conditions provide more homothetic shape modifications, revealing less impact on the management and the storage signatures.

- As a last consideration, we can note that the storage signature is more straightforward to interpret, both in terms of shape (management difficulty) and amplitude (reservoir relevance). Nevertheless, this signature only reflects the satisfaction of the objective. Its shape can be weakly informative when this objective is simple like in the case of the RLM alone - the storage signature is then almost flat throughout the year. Interpreting MSWV signatures requires a more economical reasoning about the 

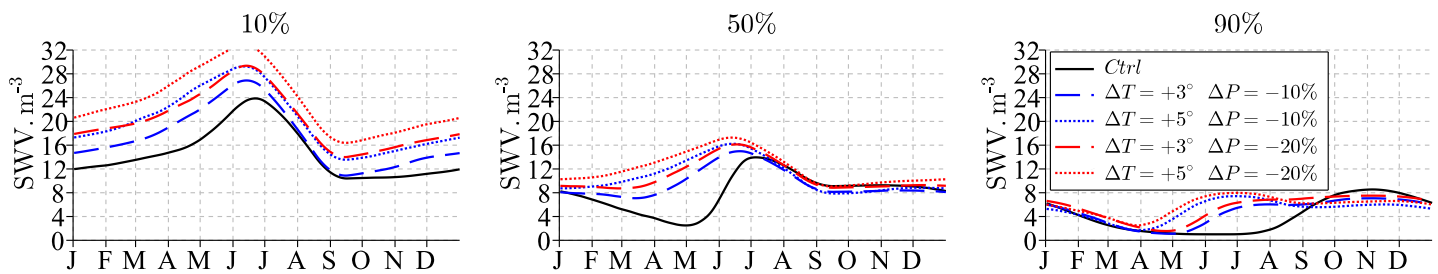

Figure 12. Sensitivity of MSWV signatures to changes of both precipitation and temperature in the case of the double-objective configuration (HEP + RLM). The different columns correspond to storage capacity levels of $10 \%$ (left), 50\% (middle) and $90 \%$ (right).

interest of water allocation in time. They express in more detail the full set of mechanisms behind the satisfaction of the assigned objective. For instance, in the case of the RLM objective alone, the MSWV signature will display the rather marked seasonality of the needed management, and not only its mere result expressed by a single reliability value, for example. In that sense, we suggest that both signatures are useful.

This study has shown some limitations, opening perspectives for future studies. There is for instance the relative complexity of the system used for the demonstration. Real water resource systems generally deal with more objectives and constraints and with a number of interconnected reservoirs. With an optimization algorithm such as dynamic programming, additional constraints and requirements can be integrated quite easily (e.g. irrigation water demand, dam safety management during floods or minimum flow maintenance for ecosystem integrity). In the case of multi-reservoir systems, MSWV will be site dependent in addition to being time and storage level dependent (Tilmant et al., 2008, 2009; Wolfgang et al., 2009).

The simulation of future hydrological scenarios was here driven by observed precipitation and temperature time series modified according to synthetic climate change scenarios using a classical perturbation methodology. The temporal variability of future meteorological variables is therefore the same as that of the historical period. In particular, no changes in the sequences of wet and dry periods are considered from seasonal to pluri-annual timescales. Such changes are however expected to be potentially as critical as changes in the means of meteorological driving variables. They at least fully determine changes in the temporal variability of natural inflows into a reservoir, a determinant factor in the analysis of the performance of the system (McMahon et al., 2006). Changes in precipitation seasonality are expected to modify the seasonality of inflows. A higher variability of annual or pluri-annual inflows to the reservoir is also expected to lead to longer and more frequent periods of resource scarcity. The influence of such regional climate modifications will be analysed considering a large set of scenarios recently developed within the RIWER2030 research project (http://www.lthe.fr/RIWER2030/). For the studied region, those scenarios are obtained using different statistical downscaling models from a suite of GCM (global circulation model) experiments (Lafaysse et al., 2014).

Finally, we note that MSWV is also frequently estimated to determine an operating strategy for the real-time management of a water system. In such a case, the MSWV can be obtained using stochastic dynamic programming in a configuration in which future inflows and water demands are unknown (e.g. Wolfgang et al., 2009). As a result of inflow variability and uncertain predictability, the MSWV is expected to increase when compared to the MSWV obtained in the configuration of the present work (Draper et al., 2003; François, 2013). MSWV signatures obtained for an uncertain future are also potentially very informative with regard to how an operational strategy is organized, what its key features are and how it could change should the climate or demand change, or both together. When they are conversely obtained for a known sequence of inflow and demand, as in the present work, MSWV signatures define the best possible manageability of the system. They are, therefore, not influenced by possible changes in the predictability of future inflows and demand. They furthermore separate in a sense the socioclimatic and the management components of the equilibrium. In that regard, analysing changes in this signature is expected to improve our understanding of modifications of the optimal storage requirement scheme for this socio-climatic context as well as modifications of system performance classically reported on the basis of a variety of performance criteria in climate change impact analyses. 


\section{Appendix A}

In deterministic dynamic programming, the optimal storage variation for each time step $t_{i}$ of the considered simulation period $\left[t_{0}, t_{N}\right]$ is identified in order to maximize the sum, over the simulation period $\left[t_{i}, t_{N}\right]$, of the current benefits, i.e. the benefits that would result from an immediate use of water at time step $t_{i}$, and of the optimal future benefits, i.e. the benefits that would result from optimal storage variations over the future simulation period $\left[t_{i+1}, t_{N}\right]$. The optimal future benefit $F_{t_{i}}\left(s_{t_{i}}\right)$ obtainable from a hypothetical reservoir level $s_{t_{i}}$ at time $t_{i}$ is often referred to as the Bellman Value for this storage and time configuration (Bellman, 1957). It is obtained from a backward recursive calculation from the future benefits estimated for time $t_{i+1}$ :

$F_{t_{i}}\left(s_{t_{i}}\right)=\left\{g\left(u_{t_{i}}, s_{t_{i}}, t_{i}\right)+F_{t_{i+1}}\left(s_{t_{i+1}}\right)\right\}$,

where the different terms are subject to upper and lower bounds and mass conservation constraints. The state and decision variables are such that

$s_{\min } \leq s_{t_{i}} \leq s_{\max }$

and

$u_{\min } \leq u_{t_{i}} \leq u_{\max }$,

where $s_{\min }$ and $s_{\max }$ are minimum and maximum bounds for water storage volumes in the reservoir and $u_{\min }$ and $u_{\max }$ the minimum and maximum bounds for release discharges. The mass conservation equation is

$s_{t_{i+1}}=s_{t_{i}}+q_{t_{i}}-u_{t_{i}}-o_{t_{i}}$,

where $q_{t_{i}}$ is the inflow to the reservoir during the period $\left[t_{i}, t_{i+1}\right]$, and $o_{t_{i}}$ the losses (evaporation above the reservoir, controlled and uncontrolled withdrawals from the reservoir for irrigation, drinking water and other uses).

A discrete approach can be used to estimate the benefit function $F_{t}(s)$ when the dimension of the state vector is not too large. An extensive discussion about the dimensionality issue is presented in Yakowitz (1982). The final result is a table that gives the future benefits for different water levels and each time step of the simulation period. For storage levels inbetween the a priori selected states, $F_{t}(s)$ can be obtained via interpolation. In our case, $F_{t}(s)$ is estimated at a daily time step and at 51 storage levels uniformly distributed between the minimum and maximum storage bounds $s_{\min }$ and $s_{\max }$. A cubic spline interpolation method is used when needed (Foufoula-Georgiou and Kitanidis, 1988).
In the present study, end values are estimated as proposed by Wolfgang et al. (2009). The duration of the simulation period is artificially increased with a fictitious $n$-year initialization period, added at the end of the simulation period. The initialization period is composed from several duplications of the final year so that the storage water values at $t_{N}$ are no longer influenced by the boundary conditions chosen at the end of the extended planning period. The storage water values at $t_{N}$ are next used to estimate the corresponding Bellman value $F_{t_{N}}(s)$ from the reciprocal function of Eq. (A1).

The derivative of the future benefit function $F_{t}(s)$ for a given storage level $s$ in the reservoir gives the optimal benefit for a future use of one additional unit of water stored at this storage level (Eq. 1). It corresponds to the marginal value of storage water for this storage level $s$ and time $t$ :

$V_{t}(s)=\frac{\partial F_{t}(s)}{\partial s}$.

As shown in Eq. (A5), the marginal value of storage water $V$ is time and storage level dependent. The MSWV signatures proposed in Sect. 5 are derived from this computation.

The above-mentioned optimization stage provides the optimal future benefit $F_{t}(s)$ for all storage levels $s$ of the statetime table. This table can be used to derive the storage water values $V$ for the same state-time grid. In a discrete approach, the derivatives are calculated with finite differences from neighbouring water level states in the table.

The storage water values can be used in a second optimization stage to identify the optimal operation decision for the current time $t_{i}$, given the water level in the reservoir $s_{t_{i}}$. This operation maximizes the following equation:

$\left\{g\left(u_{t_{i}}, s_{t_{i}}, t_{i}\right)+\left(s_{t_{i+1}}-s_{t_{i}}\right) \cdot V_{t_{i+1}}\left(s_{t_{i+1}}\right)\right\}$.

The forward iterative optimization of Eq. (A6) can therefore give the optimal sequence of storage variations, resulting reservoir water levels, benefits and penalty costs over the whole simulation horizon $\left[t_{0}, t_{N}\right]$. This simulation method is usually referred to as the water value method (e.g. Hveding, 1968). The storage signature proposed in Sect. 4 is derived from this computation. 
Acknowledgements. This work was initiated within the RIWER2030 research project on Regional Climate, Water, Energy Resources and Uncertainties from 1960 to 2030 (grant number ANR08-VULN-014-01 funded by the VMCS Program of the French National Research Agency; http://www.lthe.fr/RIWER2030/). It also contributes to the COMPLEX Project on Knowledge Based Climate Mitigation Systems for a Low Carbon Economy (European Collaborative Project FP7-ENV-2012 number: 308601; http://www.complex.ac.uk/).

Edited by: N. Ursino

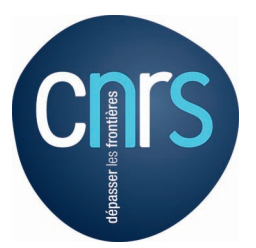

The publication of this article is financed by CNRS-INSU.

\section{References}

Alcamo, J., Moreno, J. M., Novaky, B., Binidi, M., Corobov, R., Devoy, R. J., Giannakopoulos, C., Martin, E., Olesen, J., and Shvidenko, A.: Europe, in: Climate Change 2007: Impacts, Adaptations and Vulnerability. Contribution of Working Group II to the Fourth Assessment Report of the Intergovernmental Panel on Climate Change, 541-580, Cambridge, 2007.

Ashofteh, P. S., Haddad, O. B., and Mariño, M. A.: Climate Change Impact on Reservoir Performance Indexes in Agricultural Water Supply, J. Irrig. Drainage Eng., 139, 85-97, doi:10.1061/(ASCE)IR.1943-4774.0000496, 2013.

Bellman, R.: Dynamic Programming, Princeton University Press., Defense Technical Information Center, New Jersey, 366 pp., 1957.

Bourqui, M., Mathevet, T., Gailhard, J., and Hendrickx, F.: Hydrological validation of statistical downscaling methods applied to climate model projections, IAHS-AISH publication, 344, 32-38, 2011.

Buzoianu, M., Brockwell, A. E., and Seppi, D. J.: A Dynamic Supply-Demand Model for Electricity Prices, Carnegie Mellon University,Department of statistics, available at: http://search. stat.cmu.edu/tr/tr817/tr817.pdf (last access: 11 October 2012), 2005.

Christensen, N.: Prediction of Regional scenarios and Uncertainties for Defining EuropeaN Climate change risks and Effects - Prudence Final Report, PREUDENCE EVK2-CT2001-00132, available at: http://prudence.dmi.dk (last access: October 2013), 2004.

Draper, A. J., Jenkins, M. W., Kirby, K. W., Lund, J. R., and Howitt, R. E.: Economic-engineering optimization for California water management, J. Water Resour. Plann. Manage., 129, 155-164, 2003.

Durand, Y., Laternser, M., Giraud, G., Etchevers, P., Lesaffre, B., and Merindol, L.: Reanalysis of $44 \mathrm{Yr}$ of Climate in the French Alps (1958-2002): Methodology, Model Validation, Climatology, and Trends for Air Temperature and Precipitation, J. Appl. Meteorol. Climatol., 48, 429-449, doi:10.1175/2008JAMC1808.1, 2009.
Foufoula-Georgiou, E. and Kitanidis, P. K.: Gradient dynamic programming for stochastic optimal control of multidimensional water resources systems, Water Resour. Res., 24, 1345-1359, doi:198810.1029/WR024i008p01345, 1988.

François, B.: Gestion optimale d'un réservoir hydraulique multiusages et changement climatique. Modèles, projections et incertitudes, Université de Grenoble, Grenoble, available at: http://tel.archives-ouvertes.fr/docs/00/99/70/12/PDF/33716_ FRANCOIS_2013_archivage.pdf (last access: 5 June 2014), 2013.

Gaudard, L., Gilli, M., and Romerio, F.: Climate Change Impacts on Hydropower Management, Water Resour. Manage., 27, 5143 5156, doi:10.1007/s11269-013-0458-1, 2013.

Gottardi, F., Obled, C., Gailhard, J., and Paquet, E.: Statistical reanalysis of precipitation fields based on ground network data and weather patterns: Application over French mountains, J. Hydrol., 432-433, 154-167, doi:10.1016/j.jhydrol.2012.02.014, 2012.

Hashimoto, T., Stedinger, J. R., and Loucks, D. P.: Reliability, resiliency, and vulnerability criteria for water resource system performance evaluation, Water Resour. Res., 18, 14-20, doi:10.1029/WR018i001p00014, 1982.

Hekkenberg, M., Benders, R. M. J., Moll, H. C., and Schoot Uiterkamp, A. J. M.: Indications for a changing electricity demand pattern: The temperature dependence of electricity demand in the Netherlands, Energ. Pol., 37, 1542-1551, doi:10.1016/j.enpol.2008.12.030, 2009.

Horton, P., Schaefli, B., Mezghani, A., Hingray, B., and Musy, A.: Assessment of climate-change impacts on alpine discharge regimes with climate model uncertainty, Hydrol. Process., 20, 2091-2109, doi:10.1002/hyp.6197, 2006.

Hveding, V.: Digital simulation techniques in power system planning, Econom. Plann., 8, 118-139, doi:10.1007/BF02481379, 1968.

Lafaysse, M., Hingray, B., Etchevers, P., Martin, E., and Obled, C.: Influence of spatial discretization, underground water storage and glacier melt on a physically-based hydrological model of the Upper Durance River basin, J. Hydrol., 403, 116-129, doi:10.1016/j.jhydrol.2011.03.046, 2011.

Lafaysse, M., Hingray, B., Mezghani, A., Gailhard, J., and Terray, L.: Internal variability and model uncertainty components in future hydrometeorological projections: The Alpine Durance basin, Water Resour. Res., 50, 3317-3341, doi:10.1002/2013WR014897, 2014.

Loucks, D. P., van Beek, E., Stedinger, J. R., Dijkman, J. P. M., and Villars, M. T.: Water Resources Systems Planning and Management: An Introduction to Methods, Models and Applications, Paris?: UNESCO, available at: http://ecommons.library.cornell. edu/handle/1813/2804 (last access: 23 May 2013), 2005.

Marnezy, A.: Les barrages alpins. De l'énergie hydraulique à la neige de culture, Revue de géographie alpine, J. Alpine Res., 1, 92-102, doi:10.4000/rga.422, 2008.

Masse, P.: Les réserves et la régulation de l'avenir dans la vie économique, Actualités scientifiques et industrielles 1008, Hermann, Paris, 1946.

McMahon, T., Adeloye, A., and Zhou, S.: Understanding performance measures of reservoirs, J. Hydrol., 324, 359-382, doi:10.1016/j.jhydrol.2005.09.030, 2006. 
Minville, M., Brissette, F., Krau, S., and Leconte, R.: Adaptation to Climate Change in the Management of a Canadian WaterResources System Exploited for Hydropower, Water Resour Manage, 23, 2965-2986, doi:10.1007/s11269-009-9418-1, 2009.

Morin, G., Fortin, J. P., and Charbonneau, R.: Utilisation du modèle hydrophysiographique CEQUEAU pour l'exploitation des réservoirs artificiels, IAHS Publication no 115, 176-184, 1975.

Moy, W.-S., Cohon, J. L., and ReVelle, C. S.: A Programming Model for Analysis of the Reliability, Resilience, and Vulnerability of a Water Supply Reservoir, Water Resour. Res., 22, 489498, doi:198610.1029/WR022i004p00489, 1986.

Nakicenovic, N., Alcamo, J., Davis, G., de Vries, B., Fenhann, J., Gaffin, S., Gregory, K., Grubler, A., Jung, T., Kram, T., La Rovere, E. L., Michaelis, L., Mori, S., Morita, T., Pepper, W., Pitcher, H. M., Price, L., Riahi, K., Roehrl, A., Rogner, H. H., Sankovski, A., Sclesinger, M., Shukla, P., Smith, S. J., Swart, R., van Rooijen, S., Victor, N., and Dadi, Z.: Special Report on Emissions Scenarios?: a special report of Working Group III of the Intergovernmental Panel on Climate Change, available at: http://www.osti.gov/energycitations/ servlets/purl/15009867-Kv00FB/native/ (last access: 20 April 2012), 2001.

Nash, J. E. and Sutcliffe, J. V.: River flow forecasting through conceptual models part I - A discussion of principles, J. Hydrol., 10, 282-290, doi:10.1016/0022-1694(70)90255-6, 1970.

Paiva, R. C. D., Collischonn, W., Schettini, E. B. C., Vidal, J.P., Hendrickx, F., and Lopez, A.: The Case Studies, in: Modelling the Impact of Climate Change on Water Resources, edited by: Fung, F., Lopez, A., and New, M., 136-182, John Wiley \& Sons, Ltd., available at: http://onlinelibrary.wiley.com/doi/10. 1002/9781444324921.ch6/summary (last access: 18 May 2012), 2010.

Raje, D. and Mujumdar, P. P.: Reservoir performance under uncertainty in hydrologic impacts of climate change, Adv. Water Resour., 33, 312-326, doi:10.1016/j.advwatres.2009.12.008, 2010.

Rosenberg, N. J., Brown, R. A., Izaurralde, R. C., and Thomson, A. M.: Integrated assessment of Hadley Centre (HadCM2) climate change projections on agricultural productivity and irrigation water supply in the conterminous United States, Agr. Forest Meteorol., 117, 73-96, doi:10.1016/S0168-1923(03)00025-X, 2003.

Rosenzweig, C., Strzepek, K. M., Major, D. C., Iglesias, A., Yates, D. N., McCluskey, A., and Hillel, D.: Water resources for agriculture in a changing climate: international case studies, Global Environ. Change, 14, 345-360, doi:10.1016/j.gloenvcha.2004.09.003, 2004.
Schaefli, B., Hingray, B., and Musy, A.: Climate change and hydropower production in the Swiss Alps: quantification of potential impacts and related modelling uncertainties, Hydrol. Earth Syst. Sci., 11, 1191-1205, doi:10.5194/hess-11-11912007, 2007.

Schneider, C., Laizé, C. L. R., Acreman, M. C., and Flörke, M.: How will climate change modify river flow regimes in Europe?, Hydrol. Earth Syst. Sci., 17, 325-339, doi:10.5194/hess-17-3252013, 2013.

Tilmant, A., Pinte, D., and Goor, Q.: Assessing marginal water values in multipurpose multireservoir systems via stochastic programming, Water Resour. Res., 44, W12431, doi:10.1029/2008WR007024, 2008.

Tilmant, A., Goor, Q., and Pinte, D.: Agricultural-to-hydropower water transfers: sharing water and benefits in hydropowerirrigation systems, Hydrol. Earth Syst. Sci., 13, 1091-1101, doi:10.5194/hess-13-1091-2009, 2009.

Turgeon, A.: Stochastic optimization of multireservoir operation: The optimal reservoir trajectory approach, Water Resour. Res. 43, W05420, doi:10.1029/2005WR004619, 2007.

Vachala, S.: Evaporation sur les retenues du Sud de la France (In French), Master Thesis, Université Pierre et Marie Curie, Ecole des Mines de Paris \& Ecole Nationale du Génie Rural des Eaux et des Forêts, available at: http://www.sisyphe.upmc.fr/ m2hh/ arch/memoires2008/Vachala.pdf (last access: 29 October 2013), 2008.

Veijalainen, N., Dubrovin, T., Marttunen, M., and Vehviläinen, B.: Climate Change Impacts on Water Resources and Lake Regulation in the Vuoksi Watershed in Finland, Water Resour. Manage., 24, 3437-3459, doi:10.1007/s11269-010-9614-z, 2010.

Vicuña, S., Dracup, J. A., Lund, J. R., Dale, L. L., and Maurer, E. P.: Basin-scale water system operations with uncertain future climate conditions: Methodology and case studies, Water Resour. Res., 46, W04505, doi:10.1029/2009WR007838, 2010.

Ward, F. A., Roach, B. A., and Henderson, J. E.: The Economic Value of Water in Recreation: Evidence from the California Drought, Water Resour. Res., 32, 1075-1081, doi:10.1029/96WR00076, 1996.

Wolfgang, O., Haugstad, A., Mo, B., Gjelsvik, A., Wangensteen, I., and Doorman, G.: Hydro reservoir handling in Norway before and after deregulation, Energy, 34, 1642-1651, doi:10.1016/j.energy.2009.07.025, 2009.

Yakowitz, S.: Dynamic programming applications in water resources, Water Resour. Res., 18, 673-696, doi:10.1029/WR018i004p00673, 1982. 